\title{
Platelet Membrane Glycoproteins: A Historical Review*
}

\author{
Alan T. Nurden, $\mathrm{PhD}^{1}$ \\ ${ }^{1}$ L'Institut de Rhythmologie et Modélisation Cardiaque (LIRYC), \\ Plateforme Technologique et d'Innovation Biomédicale (PTIB), \\ Hôpital Xavier Arnozan, Pessac, France

\begin{abstract}
Address for correspondence Alan T. Nurden, PhD, L'Institut de Rhythmologie et Modélisation Cardiaque, Plateforme Technologique et d'Innovation Biomédicale, Hôpital Xavier Arnozan, Avenue du HautLévèque, 33600 Pessac, France (e-mail: nurdenat@gmail.com).
\end{abstract}

Semin Thromb Hemost 2014;40:577-584.

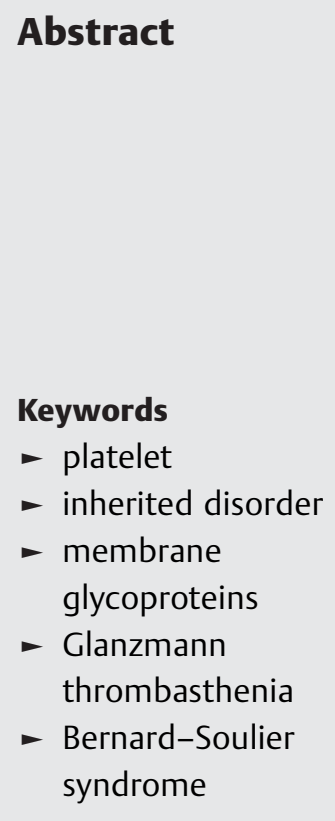

The search for the components of the platelet surface that mediate platelet adhesion and platelet aggregation began for earnest in the late 1960s when electron microscopy demonstrated the presence of a carbohydrate-rich, negatively charged outer coat that was called the "glycocalyx." Progressively, electrophoretic procedures were developed that identified the major membrane glycoproteins (GP) that constitute this layer. Studies on inherited disorders of platelets then permitted the designation of the major effectors of platelet function. This began with the discovery in Paris that platelets of patients with Glanzmann thrombasthenia, an inherited disorder of platelet aggregation, lacked two major GP. Subsequent studies established the role for the GPIIb-IIla complex (now known as integrin $\alpha_{11 b} \beta_{3}$ ) in binding fibrinogen and other adhesive proteins on activated platelets and the formation of the protein bridges that join platelets together in the platelet aggregate. This was quickly followed by the observation that platelets of patients with the Bernard-Soulier syndrome, with macrothrombocytopenia and a distinct disorder of platelet adhesion, lacked the carbohydrate-rich, negatively charged, GPIb. It was shown that GPIb, through its interaction with von Willebrand factor, mediated platelet attachment to injured sites in the vessel wall. What follows is a personal reflection on the studies that were performed in the early pioneering days.

I am very pleased to contribute to this anniversary edition of Seminars in Thrombosis $\mathcal{E}$ Hemostasis. My aim here is to provide some personal reflections on the discovery and initial characterization of the platelet membrane glycoprotein (GP) mediators of platelet aggregation and adhesion to the vessel wall. In view of space limitations, I will confine myself to the critical 25-year period from 1968 to 1983 . Most early studies were based on the hypothesis that unidentified membrane

\footnotetext{
* This article is dedicated to Professors Jacques Caen and Peter Castaldi. Jacques Caen is the father of studies on inherited disorders of platelets and gave me my chance during my early years in Paris. His knowledge and drive meant that he was always pushing back the boundaries of knowledge. Peter Castaldi was one of the early pioneers of studies on Glanzmann thrombasthenia and provided much encouragement to me during my early years in Paris. I wish them both a long and happy retirement.
}

published online June 26, 2014
Issue Theme A Short History of Thrombosis and Hemostasis: Part I (40th Year Celebratory Issue); Guest Editor, Emmanuel J. Favaloro, PhD, FFSc (RCPA).

constituents were responsible for the surface contact interactions necessary for the participation of platelets in the hemostatic plug. I will emphasize studies on inherited disorders of platelets although I will try to avoid repeating as much as possible my previous historical reviews on this subject. $^{1,2}$ The reader is also asked to note that I use the GP nomenclature of that time; GPIIb and GPIIla are now known as the integrin $\alpha_{\text {IIb }}$ and $\beta_{3}$ subunits, respectively.

\section{Platelets and the Surface Glycocalyx}

It was through the use of electron microscopy (EM) that workers such as John French in Oxford were able to define the ultrastructure of platelets and show how their morphology changed following platelet activation and during adhesion to the injured vessel wall., ${ }^{3,4}$ But it was a Danish researcher, Olaf

Copyright (c) 2014 by Thieme Medical Publishers, Inc., 333 Seventh Avenue, New York, NY 10001, USA.

Tel: +1(212) 584-4662.
DOI http://dx.doi.org/ 10.1055/s-0034-1383826. ISSN 0094-6176. 


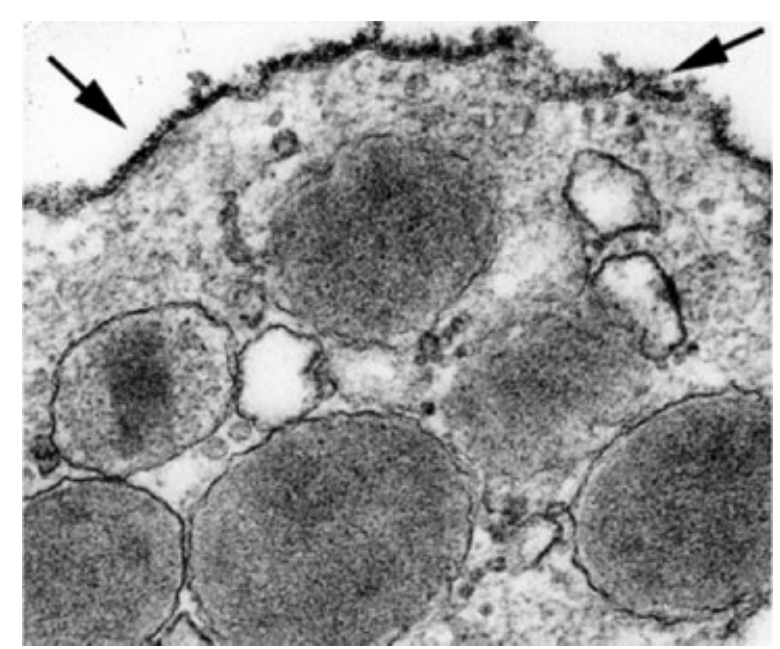

Fig. 1 An early electron microscopy study showing an electron micrograph of a platelet that had been labeled with a cationic dye. Note the enhanced labeling of the surface (heavy arrows) suggesting the presence of charged elements that were quickly shown to be largely composed of mucopolysaccharide and an acidic macroglycopeptide enriched in sialic acid. Reproduced from a slide given to the author in 1968 by the late John French (University of Oxford).

Behnke, ${ }^{5}$ who first convincingly showed that blood platelets possessed an amorphous coat extending some 150 to $200 \AA$ from the surface; a layer that was termed "glycocalyx" (-Fig. 1). In particular, Behnke noted that preservation of the coat was much improved when a cationic dye, alcian blue, or other stains such as ruthenium red or colloidal iron, were added to the glutaraldehyde fixative. Acidic mucopolysaccharides were thought the most likely contributors to the glycocalyx although a loss of staining after treatment with proteases also suggested a GP component. When platelets aggregated, the surface membranes remained separated by a gap-containing material that was proteinaceous in nature. Somewhat later, Richard Skaer in Cambridge used EM to investigate the fine structure of the contacts in platelet aggregates and highlighted $50-\mathrm{nm}$ wide intracellular spaces spanned by protein bridges attached to stubs on the platelet membrane. ${ }^{6}$ However, the individual components responsible for these structures and the platelet glycocalyx were yet to be identified.

Sialic acid is a negatively charged monosaccharide that terminates many of the O-linked and $\mathrm{N}$-linked oligosaccharide side chains of membrane GP as well as a class of glycolipids termed gangliosides. Aaron Marcus et al in New York analyzed the sialic acid-containing glycolipids of platelets and showed that gangliosides constituted $0.5 \%$ of the platelet lipids and accounted for $6 \%$ of the sialic acid found on the platelet surface. ${ }^{7}$ Nevertheless, it was concluded that the orientation and organization of platelet membrane glycolipids could be important determinants of the unique surface properties of platelets. But clearly, there were other components involved and Graham Jamieson's group in Washington brought attention to membrane GP by publishing a series of studies detailing the carbohydrate composition of glycopeptides released from platelets or isolated platelet membranes by proteases. ${ }^{8,9}$ In particular, a heavily charged sialic acidrich macroglycopeptide was identified as a major contributor to the platelet surface charge; significantly, its structure was quite different from the glycopeptides released from erythrocytes. In a personal approach, I tested the agents used by Behnke in EM as potential stains for glycopeptides released from platelets by proteases; these were separated by electrophoresis on cellulose acetate paper and then, as technology progressed, on polyacrylamide gels. ${ }^{2,10}$ Alcian blue proved to be an excellent reagent and two classes of component were detected (see Figure 1 of the review by Nurden ${ }^{2}$ ). The first comigrated with chondroitin 4- or 6-sulfate, whereas the second was no longer seen when platelets were incubated with neuraminidase, an enzyme that releases terminal negatively charged sialic acid. The second component corresponded to the macroglycopeptide previously characterized by Jamieson and his coworkers. Interestingly, charge differences were detected between the macroglycopeptide released from human platelets and from platelets of a series of primates. ${ }^{10}$ The high sialic acid content of the macroglycopeptide in human platelets suggested a rigid structure that would protrude out from the platelet surface.

Although early studies suggested that most sulfated mucopolysaccharides synthesized in megakaryocytes were stored in granules (chondroitin-4-sulfate is now known to be a major constituent of $\alpha$ granules where it complexes with platelet factor 4), evidence was also obtained for a surface pool. ${ }^{11}$ A possible contribution to the surface properties of platelets was shown by the loss of mucopolysaccharide during adenosine diphosphate (ADP)-induced platelet aggregation. ${ }^{12}$ Surprisingly, the role of surface-bound chondroitin4-sulfate of platelets has never been fully elucidated. Nevertheless, chondroitin-4-sulfate and the platelet macroglycopeptide are the major charged components of the "glycocalyx" first revealed by Behnke ${ }^{5}$ and the early EM studies were the starting point for much of the work that followed.

\section{Identification of Major Surface Membrane Glycoproteins}

The development of sodium dodecyl sulfate polyacrylamide gel electrophoresis (SDS-PAGE) allowed the study of intrinsic GP (those that possess transmembrane and cytoplasmic domains) following the solubilizing of cells or isolated membranes by the ionic detergent SDS. The migration of proteins according to their size was largely because of their uniform capacity to bind the detergent although exceptions occurred for highly glycosylated proteins. When SDS-PAGE was applied to platelets, three principal GP bands termed GPI, GPII, and GPIII were identified by carbohydrate staining using the colorimetric periodic acid-Schiff (PAS) reaction (-Fig. 2). Ralph Nachman in New York, David Phillips in Memphis, and James $\mathrm{N}$ George in San Antonio were early pioneers in this field. ${ }^{13-16}$ SDS-PAGE was even more powerful when combined with radiolabeling of surface GP. Initially, lactoperoxidase, a large ( $90 \mathrm{kDa}$ ) enzyme unable to penetrate the plasma membrane of cells, was used to catalyze the incorporation of 
A

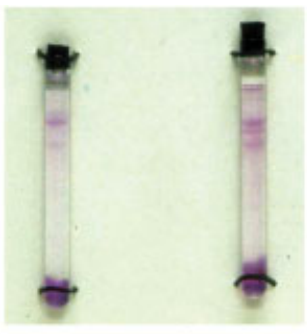

GT

Control
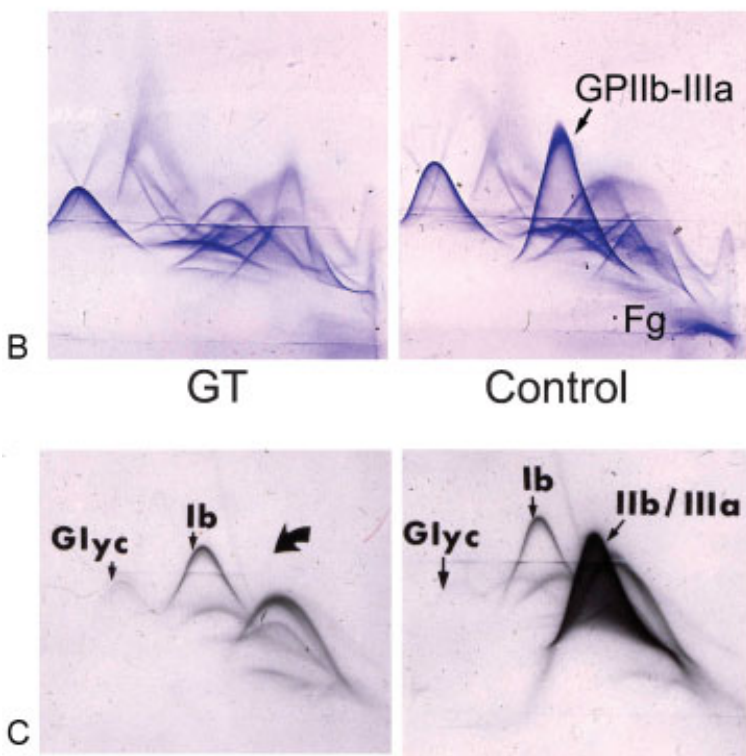

GT

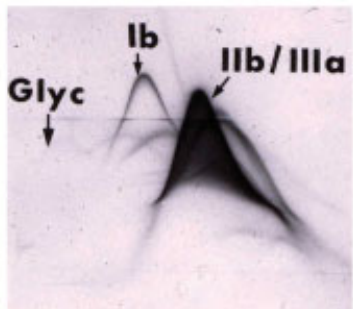

Control

Fig. 2 First studies showing a platelet GPIIb-IIla deficiency in Glanzmann thrombasthenia (GT). In panel A, an original periodate-acid-Schiff (PAS)stained tube gel obtained following sodium dodecyl sulfate polyacrylamide gel electrophoresis of platelet proteins in Paris in the summer of 1973. Note that three PAS-stained bands were clearly seen for normal platelets, while only the upper band (GPI or GPIb) was normally present on the GT platelet profile. Reproduced from Nurden et al ${ }^{27}$ with the permission of John Wiley and Sons. In panel B are shown Coomassie Blue R250 (CBR-250)-stained crossed immunoelectrophoresis (CIE) gels showing the predominant GPIIbIlla precipitate on the normal platelet pattern and its absence from the GT platelet pattern. This loss was accompanied by a parallel decrease of the immunoprecipitate given by fibrinogen $(\mathrm{Fg})$ on the GT platelet profile. This is an original photograph from the series of experiments that were first described in Hagen et al. ${ }^{20}$ Panel $\mathrm{C}$ shows autoradiographs obtained after platelets had been labeled with ${ }^{125}$ I by the lactoperoxidase-catalyzed procedure. These studies were performed on platelet proteins extracted into Triton X-100 and electrophoresed in the second dimension against the isolated immunoglobulins of a rabbit antibody to normal human platelets.

${ }^{125}$ I into tyrosine residues exposed at the platelet surface. The principle ${ }^{125}$ I-labeled constituents revealed by autoradiography proved to be GPIIb (a major component of the previously termed GPII) and GPIIIa (a major component of GPIII) (-Figs. 3 and 4). Contrasting with this enzymatic approach, direct chemical labeling was achieved using diazotized $\left({ }^{125} \mathrm{I}\right)$ diiodosulfanilic acid although the principle labeled surface constituents remained the same. ${ }^{16}$ An alternative approach, first applied to platelets by Kenneth Clemetson (Berne) and John McGregor (Lyon), along with their coworkers, was to
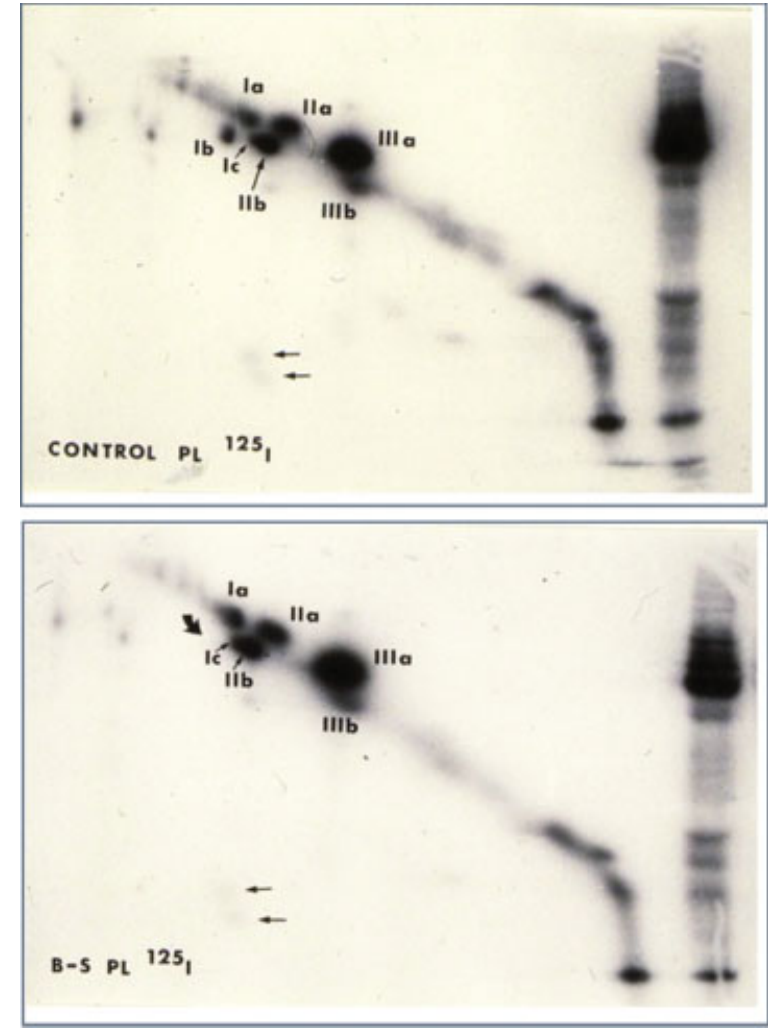

Fig. 3 Mapping of the surface composition of platelets using twodimensional nonreduced/reduced sodium dodecyl sulfate polyacrylamide gel electrophoresis. The surface proteins of washed normal and Bernard-Soulier syndrome (BSS) platelets were labeled with ${ }^{125} \mathrm{I}$ by lactoperoxidase-catalyzed iodination. Platelet proteins were first separated by rod gel electrophoresis (left to right) without disulphide reduction. Disulfides were then reduced within the rod gels that were then overlayered onto a slab before the second dimension electrophoresis. Radiolabeled proteins were detected by autoradiography. Note the specific absence of GPIb from the BSS platelet pattern while GPIIb and GPIIla were normally located. Reproduced from Nurden et $\mathrm{al}^{37}$ with permission from the American Society for Clinical Investigation.

detect carbohydrate residues in the oligosaccharide residues of the GP either using ${ }^{125}$ I-labeled lectins after SDS-PAGE or by a prelabeling procedure that involved the enzymatic removal of sialic acid by neuraminidase to expose galactose residues that were then reduced using sodium $\left({ }^{3} \mathrm{H}\right)$-borohydride. ${ }^{17}$ Incorporated ${ }^{3} \mathrm{H}$ was located by fluorography and using this approach GPIb (the major component of GPI) predominated as a result of its high content of O-linked oligosaccharide chains (-Fig. 5).

\section{Two-Dimensional Acrylamide Gel Electrophoresis}

Resolution of surface constituents was greatly favored when two-dimensional SDS-PAGE procedures were applied to platelets. Phillips and Agin first migrated SDS-soluble platelet extracts in a first dimension tube gel, then reduced disulfides before second dimension electrophoresis across a slab gel. ${ }^{18}$ Reducing disulfides resulted in the separation of the small 


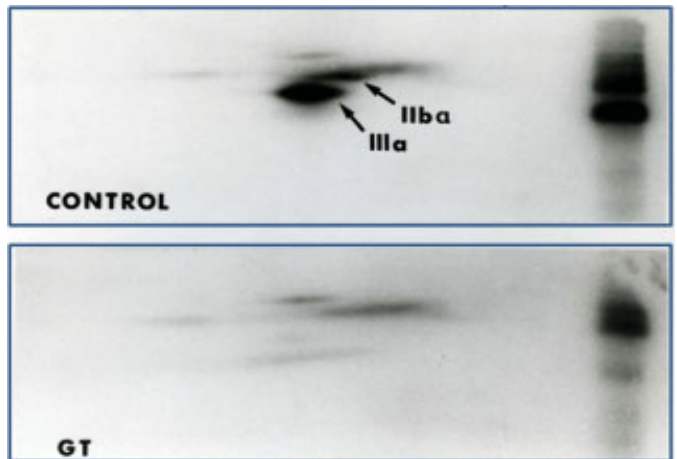

Fig. 4 Proteomic analysis of platelet proteins in Paris in the early 1980 s. The surface proteins of platelets were labeled with ${ }^{125} I$ and the platelets solubilized using a nonionic detergent and the proteins separated by isoelectric focusing in rod gels (left to right) prior to separation after disulfide reduction by sodium dodecyl sulfate polyacrylamide gel electrophoresis in slab gels (migration top to bottom) in the second dimension. Equivalent Coomassie blue R250-stained gels are shown in Nurden. ${ }^{2}$ Here, we show the absence of the spots given by the GPIIb $\alpha$ heavy chain and GPIIla from the Glanzmann thrombasthenia (GT) platelet pattern. Quite remarkable is how GPIIb and GPIIla are such dominant features of the platelet surface.

light or $\beta$-chains from the heavy or $\alpha$-chains from some GP subunits (GPIb, GPIIb, GPIa, and GPIc), whereas the loss of intramolecular disulfides of other membrane GPs (GPIIIa) actually slowed their migration. These migration changes resulted in many GPs migrating away from the diagonal. An illustration of this procedure from my work is shown in -Fig. 3. A further advance came with the introduction of isoelectric focusing in the first dimension after solubilizing platelets using nonionic detergents. The first dimension isoelectric focusing gels were then incubated with SDS with or without disulfide reduction and the proteins separated in a second dimension slab gel by SDS-PAGE. ${ }^{17}$ The application of such high-resolution procedures to platelets whose surface components were prelabeled with ${ }^{125} \mathrm{I}$ or ${ }^{3} \mathrm{H}$ led to protein separation on the basis of both charge and size ( - Fig. 4). In fact, these procedures were the start of proteomic analysis of platelet proteins as performed today.

\section{Crossed Immunoelectrophoresis}

The use of SDS-PAGE has the disadvantage that SDS is denaturing and so noncovalently linked complexes are dissociated. This is not so with some nonionic detergents. Hagen and associates in Oslo made use of this property to analyze platelet proteins by crossed immunoelectrophoresis (CIE).$^{19,20}$ In this procedure, detergent-soluble proteins were first separated by electrophoresis in agarose (in the presence of detergent) and then migrated in a second dimension against a rabbit antiserum prepared against washed platelets. - Fig. 2 shows a typical pattern with immunoprecipitates highlighted by coloration with Coomassie Blue R250. Individual precipitates were excised thereby permitting the identification of those given by major membrane antigens. Significantly, ${ }^{125}$ I-labeled GPIIb and GPIIla colocalized to the same precipitate which was quite distinct from that given by

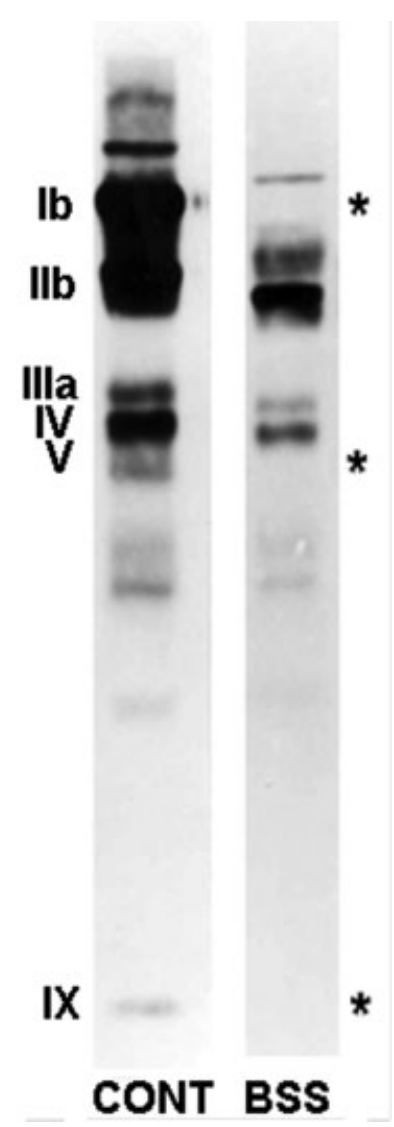

Fig. 5 Analysis of the surface composition of Bernard-Soulier syndrome (BSS) platelets after radiolabeling sugar residues. After sequential treatment of platelets with neuraminidase, galactose oxidase, and sodium $\left({ }^{3} \mathrm{H}\right)$-borohydride, the platelets were solubilized with sodium dodecyl sulfate (SDS) and separated by sodium dodecyl sulfate polyacrylamide gel electrophoresis before the location of ${ }^{3} \mathrm{H}$ by fluorography (Nurden et $\mathrm{a}^{23}$ ). Note how with this procedure GPIb dominates the control platelet pattern. As well as the absence of GPIb, it is also possible to distinguish the deficits of GPV and GPIX from the BSS platelet profile.

GPIb. Thomas Kunicki, working with me in Paris made the fundamental discovery that GPIIb and GPIIla were present as $\mathrm{a} \mathrm{Ca}^{2+}$-dependent dimer in the platelet membrane. ${ }^{21,22}$ Seen retrospectively, this was a major step in the identification of the GPIIb-IIIa complex as an integrin. CIE was a highly adaptable procedure and antigen migration changes in the first dimension helped identify platelet GPs as, for example, the marked slowing of GPIb after neuraminidase treatment of platelets. ${ }^{23}$ Autoradiography revealed ${ }^{125}$ I-labeled surface components ( - Fig. 2) while the incorporation of a precipitating monospecific polyclonal antibody in a thin intermediate gel in the second dimension allowed the identification of specific proteins, as did the incorporation of ${ }^{125}$ I-labeled monoclonal antibodies (MoAbs), lectins or ligands. ${ }^{19-23}$

\section{Glanzmann Thrombasthenia and the Bernard-Soulier Syndrome}

Recognizing the logic that platelets possess surface components that specifically mediate platelet aggregation and 
platelet adhesion, Jacques Caen in Paris pioneered studies on inherited disorders of platelets. They confirmed how Glanzmann thrombasthenia (GT), the most common of these disorders, was characterized by a defective platelet aggregation in response to all physiologic agonists. Quite simply, platelets of these patients were unable to form the cohesive bonds that linked them together during the process of aggregation. Not only was aggregation affected, in most patients clot retraction was also absent, although occasionally it was partial or subnormal. ${ }^{24}$ Fibrinogen $(\mathrm{Fg})$ and $\mathrm{Ca}^{2+}$ were already known cofactors of ADP-induced human platelet aggregation. ${ }^{25,26}$ GT offered the chance to identify the surface constituent mediating platelet aggregation, and in 1973, this led me to Paris to examine the membrane GP of platelets of three GT patients using the electrophoretic techniques that were available at the time. The alcian blue-staining macroglycopeptide derived from GPI (GPIb) was normally detected, but after SDS-PAGE, the PAS-stained bands corresponding to GPII (GPIIb) and GPIII (GPIIIa) were much reduced in intensity for all the three patients (an original gel is illustrated in - Fig. 2). ${ }^{27,28}$ In this way, the link between membrane GP and platelet aggregation was established. Phillips et al (also in Paris) confirmed these results and improved the analysis using ${ }^{125}$ I-labeled GT platelets with proteins separated by single or bidimensional SDS-PAGE. ${ }^{18,29}$ Quite clearly, the surface of GT platelets was deficient in two major constituents (illustrated from my work in -Figs. 3 and $\mathbf{4}$ ). When CIE was applied to the analysis of GT platelets a dominant immunoprecipitate was missing from the profile; overall, after much work, it was concluded that GT platelets lacked the $\mathrm{Ca}^{2+}$-dependent GPIIb-IIla complex ( - Fig. 2). ${ }^{20-22}$ Shulman and Karpatkin in New York, who also used CIE, confirmed this conclusion. ${ }^{30}$ Incidentally, the sensitivity of CIE permitted the detection of residual amounts of GPIIb-IIIa in the platelets of some GT patients confirming heterogeneity in the disease..$^{20}$ Likewise, CIE also substantiated much earlier studies from Peter Castaldi and Jacques Caen that platelets of most, but not all, GT patients lacked an intracellular secretable store of $\mathrm{Fg}-\mathrm{a}$ finding that led to the definition of type I and type II disease. ${ }^{31}$

The question quickly turned to the role of the sialic acidrich GPI (GPIb). Jean Bernard and Jean Pierre Soulier in Paris had identified a giant platelet disorder, rapidly called Bernard-Soulier syndrome (BSS), where giant platelets and thrombocytopenia were accompanied by decreased surface sialic acid levels and an inability of platelets to interact with bovine Factor VIII (containing von Willebrand factor [VWF]) or with the antibiotic, ristocetin, in the presence of plasma. ${ }^{32-34}$ It was therefore logical to also study the surface GP of BSS platelets, and so I returned to Paris in 1974 to perform this work. It was quickly apparent that platelets from these patients lacked GPI (GPIb) and failed to release the alcian blue-staining macroglycopeptide; in contrast, GPII (GPIIb) and GPIII (GPIIIa) were normally present. As platelet function testing improved, the role of VWF in platelet adhesion was established. Harvey Weiss in New York showed that BSS platelets had a defective flow-dependent attachment to exposed subendothelium, a discovery that highlighted the importance of the GPIb-VWF adhesion axis. ${ }^{35}$ Although others also showed a GPI defect in BSS platelets, difficulties in separating the large platelets from leukocytes led to controversy about the specificity of the defect with leukocyte DNA and protease contaminations leading to secondary modifications of the BSS platelet protein profiles. ${ }^{30,36}$ Doubts about the specificity of the GPIb defect were quickly removed by studies combining lactoperoxidase-catalyzed ${ }^{125}$ I-labeling or ${ }^{3} \mathrm{H}$-labeling with CIE or one- and two-dimensional SDSPAGE procedures (- Fig. 5) ${ }^{20,37,38}$ GPIb was rapidly established as a major functional determinant of the platelet surface. It was also quickly apparent that the major functional chain, GPIb $\alpha$ was transported to the platelet surface linked to smaller subunits; findings that resulted in the identification of the GPIb-IX-V complex. Significantly, an incomplete synthesis of the O-linked oligosaccharide chains of GPIb $\alpha$ associated with a defective galactosyltransferase in platelets of donors with the so-called Tn-syndrome, resulted in neither giant platelets nor a defect in ristocetin-induced platelet agglutination but led to thrombocytopenia and decreased platelet survival. ${ }^{23,39}$

\section{How Platelets Fulfill Their Role in Thrombus Formation}

The earlier noted findings describe how studies on inherited platelet disorders led to the identification of key membrane receptors involved in platelet adhesion and aggregation mechanisms. But what were the molecular mechanisms behind their mode of action?

\section{Platelet Aggregation}

Studies by several workers including Gérard Marguerie, Edward Plow, and Mark Ginsberg in the Scripps Clinic in La Jolla (US) as well as Joel Bennett in Philadelphia showed how radiolabeled $\mathrm{Fg}$ and other adhesive proteins (initially VWF and fibronectin) bound in a saturating and highly specific manner to GPIIb-IIIa on stimulated platelets. ${ }^{40-43}$ Significantly, Barry Coller (New York) and his colleagues were able to inhibit platelet aggregation by preventing Fg binding to GPIIb-IIla on activated platelets with MoAbs reacting with complexdependent determinants on GPIIb-IIIa. ${ }^{44,45}$ In the blood stream, protein sources were plasma and, in the event of platelet secretion, their $\alpha$-granules. Nonetheless, early indications suggested that the aggregation mechanism was not so straightforward as an adhesive protein-dependent simple cross-linking of GPIIb-IIIa complexes on adjacent platelets. For example, Kent Gartner et al in Memphis (US) postulated that thrombin-induced platelet aggregation was mediated by a membrane-bound lectin. ${ }^{46}$ This was soon identified as thrombospondin-1 (TSP-1), a secreted $\alpha$-granule protein virtually absent from plasma, a finding nicely confirmed by Phillips et al who performed lactoperoxidase-catalyzed ${ }^{125}$ I-labeling of platelets during thrombin-induced platelet activation. ${ }^{47}$ It is interesting to note in these studies just how Fg and TSP predominate on thrombin-activated platelets. Overall, these findings led to the concept that $\mathrm{Ca}^{2+}$-dependent $\mathrm{Fg}$ binding was at the basis of ADP-induced platelet aggregation, whereas 
with strong agonists, such as thrombin or collagen, $\mathrm{Fg}$ is joined by other adhesive proteins to promote receptor clustering and the formation of more compact attachment sites. Such interactions provide the molecular basis of the bridges that were initially described morphologically by Skaer et al. ${ }^{6}$

\section{Platelet Vessel Wall Attachment}

The early characterization of the molecular basis of von Willebrand disease and the identification of qualitative or quantitative defects of VWF involved both in platelet attachment to the vessel wall and as a carrier of FVIII, helped enhance our understanding of how platelets accumulate at sites of vascular injury. ${ }^{48-51}$ Zaverio Ruggeri and Ted Zimmerman in La Jolla (USA) and Harvey Gralnick in Washington (USA) were early pioneers in this field whereas Hans Baumgartner (Basle, Switzerland), Harvey Weiss and Dominique Meyer (Paris) all contributed to show how VWF was important for platelet adhesion at high shear rate. ${ }^{35,52}$ Many early studies characterizing the interaction of VWF with platelets involved ristocetin-induced platelet agglutination although it was quickly recognized that VWF could bind not only to GPIb but also GPIIb-IIIa. ${ }^{51}$ MoAbs to GPIb blocked both ristocetin-induced platelet agglutination and high shear-dependent adhesion by preventing the binding of VWF to GPIb. ${ }^{53,54}$ So the concept was proven that platelets attach to injured sites in the vessel wall by attaching to VWF and that this is an initial step of thrombus formation that then led to adhesive protein binding to GPIIb-IIIa. ${ }^{55}$

\section{Historical Discoveries As Seen in Their Current Perspective}

It is quite remarkable that so many of the early studies still stand up in 2014. Their significance grew in importance when it was shown that the mechanisms responsible for platelet function in hemostasis were also pathologically involved in ischemic syndromes. Anti-GPIIb-IIIa antagonists arrived in the clinic and have played a major role in saving lives of patients with acute ischemic disease. ${ }^{56,57}$ They mainly act by blocking unoccupied surface GPIIb-IIIa (now referred to as the $\alpha_{\mathrm{IIb}} \beta_{3}$ integrin) and preventing platelet aggregation and platelet incorporation into a growing thrombus. But antiGPIIb-IIla acting drugs also induce a bleeding risk and in some ways mimic GT. While drugs blocking GPIb and platelet adhesion offer promise in animal models, they surprisingly have yet to be adequately tested in the clinic. ${ }^{58}$ Platelet deficiency of the P2Y12R receptor results in a mild bleeding syndrome and pharmacological blockade of this pathway implicated in the formation of stable platelet aggregates initiated by ADP has received widespread use particularly in preventing arterial thrombosis in patients at risk. ${ }^{59,60}$ The identification of GPVI as a major collagen receptor, whose absence gives rise to little bleeding has raised hope that antiplatelet drugs can be produced that will act without inducing bleeding. ${ }^{61}$ When occupied $\alpha_{\mathrm{IIb}} \beta_{3}$ form bridges between aggregating platelets, a new wave of signaling (termed "outside-in signaling") promotes new contact interactions between newly identified molecules such as ephrins and eph kinases, SLAM family proteins, and semaphorin $4 \mathrm{D} .{ }^{62,63}$ How inhibition of these proteins will contribute to aggregate instability or dissolution is unknown, while the development of a drug that will specifically block or reverse the activated $\alpha_{\mathrm{IIb \beta} 3}$ clasp will represent a significant advance. Finally, the inhibition of biologically active proteins secreted from platelets to counteract ischemic or inflammatory events offers a novel therapeutic approach particularly for cerebrovascular disease. ${ }^{64}$ Accordingly, much remains to be done and these are indeed exciting times.

\section{References}

1 Nurden AT, Phillips DR, George JN. Platelet membrane glycoproteins: historical perspectives. J Thromb Haemost 2006;4(1):3-9

2 Nurden AT. Platelet membrane glycoproteins: a look back into the past and a view to the future. Thromb Haemost 2007; 98(1):49-54

3 French JE. Blood platelets: morphological studies on their properties and life cycle. Br J Haematol 1967;13(4):595-602

4 Sheppard BL, French JE. Platelet adhesion in rabbit arteries observed by scanning and transmission electron microscopy. Nature 1970;225(5237):1054-1055

5 Behnke O. Electron microscopical observations on the surface coating of human blood platelets. J Ultrastruct Res 1968;24(1): 51-69

6 Skaer RJ, Emmines JP, Skaer HB. The fine structure of cell contacts in platelet aggregation. J Ultrastruct Res 1979;69(1):28-42

7 Marcus AJ, Ullman HL, Safier LB. Studies on human platelet gangliosides. J Clin Invest 1972;51(10):2602-2612

8 Pepper DS, Jamieson GA. Studies on glycoproteins. 3. Isolation of sialylglycopeptides from human platelet membranes. Biochemistry 1969;8(8):3362-3369

9 Pepper DS, Jamieson GA. Isolation of a macroglycopeptide from human platelets. Biochemistry 1970;9(19):3706-3713

10 Nurden AT. Platelet macroglycopeptide. Nature 1974;251(5471): 151-153

11 MacPherson GG. Synthesis and localization of sulphated mucopolysaccharide in megakaryocytes and platelets of the rat, an analysis by electron-microscope autoradiography. J Cell Sci 1972;10(3):705-717

12 Ward JV, Radojewski-Hutt AM, Packham MA, Haslam RJ, Mustard JF. Loss of sulfated proteoglycan from the surface of rabbit platelets during adenosine 5'-diphosphate-induced aggregation. Lab Invest 1976;35(4):337-342

13 Nachman RL, Ferris B. Studies on the proteins of human platelet membranes. J Biol Chem 1972;247(14):4468-4475

14 Phillips DR. Effect of trypsin on the exposed polypeptides and glycoproteins in the human platelet membrane. Biochemistry 1972;11(24):4582-4588

15 Nachman RL, Hubbard A, Ferris B. Iodination of the human platelet membrane. Studies of the major surface glycoprotein. J Biol Chem 1973;248(8):2928-2936

16 George JN, Potterf RD, Lewis PC, Sears DA. Studies on platelet plasma membranes. I. Characterization of surface proteins of human platelets labeled with diazotized (125i)-diiodosulfanilic acid. J Lab Clin Med 1976;88(2):232-246

17 McGregor JL, Clemetson KJ, James E, et al. Glycoproteins of platelet membranes from Glanzmann's thrombasthenia. A comparison with normal using carbohydrate-specific or protein-specific labelling techniques and high-resolution two-dimensional gel electrophoresis. Eur J Biochem 1981;116(2):379-388

18 Phillips DR, Agin PP. Platelet membrane defects in Glanzmann's thrombasthenia. Evidence for decreased amounts of two major glycoproteins. J Clin Invest 1977;60(3):535-545 
19 Hagen I, Bjerrum OJ, Solum NO. Characterization of human platelet proteins solubilized with Triton X-100 and examined by crossed immunoelectrophoresis. Reference patterns of extracts from whole platelets and isolated membranes. Eur J Biochem 1979;99(1):9-22

20 Hagen I, Nurden A, Bjerrum OJ, Solum NO, Caen J. Immunochemical evidence for protein abnormalities in platelets from patients with Glanzmann's thrombasthenia and Bernard-Soulier syndrome. J Clin Invest 1980;65(3):722-731

21 Kunicki TJ, Nurden AT, Pidard D, Russell NR, Caen JP. Characterization of human platelet glycoprotein antigens giving rise to individual immunoprecipitates in crossed-immunoelectrophoresis. Blood 1981;58(6):1190-1197

22 Kunicki TJ, Pidard D, Rosa JP, Nurden AT. The formation of Ca++dependent complexes of platelet membrane glycoproteins IIb and IIIa in solution as determined by crossed immunoelectrophoresis. Blood 1981;58(2):268-278

23 Nurden AT, Dupuis D, Pidard D, Kieffer N, Kunicki TJ, Cartron JP. Surface modifications in the platelets of a patient with alpha-Nacetyl-D-galactosamine residues, the Tn-syndrome. J Clin Invest 1982;70(6):1281-1291

24 Caen JP, Castaldi PA, Leclerc JC, et al. Congenital bleeding disorders with long bleeding time and normal platelet count. I. Glanzmann's thrombasthenia. Am J Med 1966;41(1):4-26

25 Born GVR, Cross MJ. Effects of inorganic ions and of plasma proteins on the aggregation of blood platelets by adenosine diphosphate. J Physiol 1964;170:397-414

26 Mustard JF, Packham MA, Kinlough-Rathbone RL, Perry DW, Regoeczi E. Fibrinogen and ADP-induced platelet aggregation. Blood 1978;52(2):453-466

27 Nurden AT, Caen JP. An abnormal platelet glycoprotein pattern in three cases of Glanzmann's thrombasthenia. Br J Haematol 1974; 28(2):253-260

28 Nurden AT, Caen JP. Specific roles for platelet surface glycoproteins in platelet function. Nature 1975;255(5511):720-722

29 Phillips DR, Jenkins CS, Lüscher EF, Larrieu M. Molecular differences of exposed surface proteins on thrombasthenic platelet plasma membranes. Nature 1975;257(5527):599-600

30 Shulman S, Karpatkin S. Crossed immunoelectrophoresis of human platelet membranes. Diminished major antigen in Glanzmann's thrombasthenia and Bernard-Soulier syndrome. J Biol Chem 1980;255(9):4320-4327

31 Castaldi PA, Caen J. Platelet fibrinogen. J Clin Pathol 1965;18(5): 579-585

32 Bernard J, Soulier JP. Sur une nouvelle variété de dystrophie thrombocytairehémoragipare congénitale. Sem Hop 1948; 24(Spec. No.):3217-3223

33 Gröttum KA, Solum NO. Congenital thrombocytopenia with giant platelets: a defect in the platelet membrane. Br J Haematol 1969; 16(3):277-290

34 Bithell TC, Parekh SJ, Strong RR. Platelet-function studies in the Bernard-Soulier syndrome. Ann N Y Acad Sci 1972;201:145-160

35 Weiss HJ, Tschopp TB, Baumgartner HR, Sussman II, Johnson MM, Egan JJ. Decreased adhesion of giant (Bernard-Soulier) platelets to subendothelium. Further implications on the role of the von Willebrand factor in hemostasis. Am J Med 1974;57(6):920-925

36 Jenkins CS, Phillips DR, Clemetson KJ, Meyer D, Larrieu MJ, Lüscher EF. Platelet membrane glycoproteins implicated in ristocetininduced aggregation. Studies of the proteins on platelets from patients with Bernard-Soulier syndrome and von Willebrand's disease. J Clin Invest 1976;57(1):112-124

37 Nurden AT, Dupuis D, Kunicki TJ, Caen JP. Analysis of the glycoprotein and protein composition of Bernard-Soulier platelets by single and two-dimensional sodium dodecyl sulfate-polyacrylamide gel electrophoresis. J Clin Invest 1981;67(5):1431-1440

38 Clemetson KJ, McGregor JL, James E, Dechavanne M, Lüscher EF. Characterization of the platelet membrane glycoprotein abnormalities in Bernard-Soulier syndrome and comparison with normal by surface-labeling techniques and high-resolution twodimensional gel electrophoresis. J Clin Invest 1982;70(2):304-311

39 Cartron JP, Nurden AT. Galactosyltransferase and membrane glycoprotein abnormality in human platelets from Tn-syndrome donors. Nature 1979;282(5739):621-623

40 Marguerie GA, Plow EF, Edgington TS. Human platelets possess an inducible and saturable receptor specific for fibrinogen. J Biol Chem 1979;254(12):5357-5363

41 Bennett JS, Vilaire G. Exposure of platelet fibrinogen receptors by ADP and epinephrine. J Clin Invest 1979;64(5):1393-1401

42 Ginsberg MH, Painter RG, Forsyth J, Birdwell C, Plow EF. Thrombin increases expression of fibronectin antigen on the platelet surface. Proc Natl Acad Sci U S A 1980;77(2):1049-1053

43 Plow EF, Srouji AH, Meyer D, Marguerie G, Ginsberg MH. Evidence that three adhesive proteins interact with a common recognition site on activated platelets. J Biol Chem 1984; 259(9):5388-5391

44 Coller BS, Peerschke EI, Scudder LE, Sullivan CA. A murine monoclonal antibody that completely blocks the binding of fibrinogen to platelets produces a thrombasthenic-like state in normal platelets and binds to glycoproteins IIb and/or IIIa. J Clin Invest 1983;72(1): 325-338

45 Pidard D, Montgomery RR, Bennett JS, Kunicki TJ. Interaction of AP-2, a monoclonal antibody specific for the human platelet glycoprotein IIb-IIIa complex, with intact platelets. J Biol Chem 1983;258(20):12582-12586

46 Gartner TK, Williams DC, Minion FC, Phillips DR. Thrombininduced platelet aggregation is mediated by a platelet plasma membrane-bound lectin. Science 1978;200(4347):1281-1283

47 Phillips DR, Jennings LK, Edwards HH. Identification of membrane proteins mediating the interaction of human platelets. J Cell Biol 1980;86(1):77-86

48 Hoyer LW. Von Willebrand's disease. Prog Hemost Thromb 1976; 3:231-287

49 Ruggeri ZM, Zimmerman TS. Variant von Willebrand's disease: characterization of two subtypes by analysis of multimeric composition of factor VIII/von Willebrand factor in plasma and platelets. J Clin Invest 1980;65(6):1318-1325

50 Gralnick HR, Williams SB, Morisato DK. Effect of multimeric structure of the factor VIII/von Willebrand factor protein on binding to platelets. Blood 1981;58(2):387-397

51 Ruggeri ZM, De Marco L, Gatti L, Bader R, Montgomery RR. Platelets have more than one binding site for von Willebrand factor. J Clin Invest 1983;72(1):1-12

52 Baumgartner HR, Tschopp TB, Meyer D. Shear rate dependent inhibition of platelet adhesion and aggregation on collagenous surfaces by antibodies to human factor VIII/von Willebrand factor. Br J Haematol 1980;44(1):127-139

53 Coller BS, Peerschke EI, Scudder LE, Sullivan CA. Studies with a murine monoclonal antibody that abolishes ristocetin-induced binding of von Willebrand factor to platelets: additional evidence in support of GPIb as a platelet receptor for von Willebrand factor. Blood 1983;61(1):99-110

54 Ruan C, Tobelem G, McMichael AJ, et al. Monoclonal antibody to human platelet glycoprotein I. II. Effects on human platelet function. Br J Haematol 1981;49(4):511-519

55 George JN, Nurden AT, Phillips DR. Molecular defects in interactions of platelets with the vessel wall. N Engl J Med 1984;311(17): 1084-1098

56 Coller BS, Shattil SJ. The GPIIb/IIIa (integrin alphallbbeta3) odyssey: a technology-driven saga of a receptor with twists, turns, and even a bend. Blood 2008;112(8):3011-3025

57 Bledzka K, Smyth SS, Plow EF. Integrin $\alpha$ IIb $\beta 3$ : from discovery to efficacious therapeutic target. Circ Res 2013;112(8):1189-1200

58 Vanhoorelbeke K, Ulrichts H, Van de Walle G, Fontayne A, Deckmyn $\mathrm{H}$. Inhibition of platelet glycoprotein Ib and its antithrombotic potential. Curr Pharm Des 2007;13(26):2684-2697 
59 Hollopeter G, Jantzen HM, Vincent D, et al. Identification of the platelet ADP receptor targeted by antithrombotic drugs. Nature 2001;409(6817):202-207

60 Michelson AD. Antiplatelet therapies for the treatment of cardiovascular disease. Nat Rev Drug Discov 2010;9(2): 154-169

61 Nieswandt B, Pleines I, Bender M. Platelet adhesion and activation mechanisms in arterial thrombosis and ischaemic stroke. J Thromb Haemost 2011;9(Suppl 1):92-104
62 Brass LF, Wannemacher KM, Ma P, Stalker TJ. Regulating thrombus growth and stability to achieve an optimal response to injury. J Thromb Haemost 2011;9(Suppl 1):66-75

63 Jackson SP. Arterial thrombosis-insidious, unpredictable and deadly. Nat Med 2011;17(11):1423-1436

64 Deppermann C, Cherpokova D, Nurden P, et al. Gray platelet syndrome and defective thrombo-inflammation in Nbeal2-deficient mice. J Clin Invest 2013 